\title{
A swirling jet from a nozzle with tangential inlets and its characteristics in breaking-up rocks
}

\author{
Yang Yongyin*, Zou Deyong, Sun Weiliang, Li Xinhui and Niu Sicheng \\ School of Petroleum Engineering, China University of Petroleum (East China), Qingdao, Shandong 266555, China \\ (C) China University of Petroleum (Beijing) and Springer-Verlag Berlin Heidelberg 2012
}

\begin{abstract}
In order to apply a swirling jet to a PDC drill bit, the nozzle performance influenced by nozzle inlet geometric parameters and rock breaking tests under submerged conditions were studied. Numerical simulation was used to study the influence of the nozzle structure on the swirling intensity and nozzle discharge coefficient. Simulation results indicate that spreading angle of the swirling jet is greater than that of the non-swirling jet, and the swirling intensity of the jet is strongly influenced by the length of the nozzle body but weakly by the number of tangential inlets. Rock breaking tests were conducted to evaluate the performance of the swirling jet. It is found that the swirling jet shows a lower threshold pressure to break the rock samples and could break rock more efficiently compared with the non-swirling jet.
\end{abstract}

Key words: Nozzle, jet, swirling intensity, discharge coefficient, simulation, rock breaking tests

\section{Introduction}

Waterjet assisted drilling is an effective method for improving the rate of penetration (ROP) during drilling oil and gas wells (Shen, 1998; Shen et al, 2006; Yang et al, 2002; 2006). When drilling with polycrystalline diamond compact (PDC) bits, the bit pressure drop is generally moderate, and the drilling fluid jets are commonly issued from conventional cone nozzles. Applying new types of jet nozzles in a PDC bit improves the bit hydraulic efficiency and drilling performance (Yang et al, 2010).

Previous research shows that swirling jets with typical velocity and pressure distributions, generally cause cavitation and apply shear force on the surface of rocks impacted, resulting in a sharp drop in the threshold pressure of the rock (i.e., the pressure necessary to break the rock) and a significant increase in the rock-breaking efficiency (Yang et al, 1999a; 2001; 2010). This technology has been successfully applied in the drilling of the ultra-short radius horizontal wells in the Liaohe, Shengli, and Jiangsu oilfields (Yang et al, 1999a; 2010).

Relevant research also indicates that the angle of spread for the swirling jet was found to be greater than that of the non-swirling jet because of its centrifugal flow, which helps to increase the jet impact area (Yang et al, 1999b; Yang et al, 2005a). In addition, compared with the non-swirling jet, the swirling jet has stronger tangential and radial velocity components across the bottom surface, which can effectively improve the cross flow field and the bottom hole cleaning.

*Corresponding author. email: yangyy@upc.edu.cn

Received October 25, 2010
Based on previous studies of the swirling jet and the hydraulics of PDC bits (Taylor et al, 1999), the application of the swirling jet to PDC bits would improve ROP.

\section{Numerical simulation of the swirling jet from nozzles with tangential inlets}

\subsection{Building and meshing of the computational model for flow in the nozzle and jet flow}

CFD software-FLUENT (developed by FLUENT Company, 1983) was used to simulate the special flow field. A three-dimensional flow field model was developed to accommodate the nonzero velocity components in each direction of the swirling flow (Zhou et al, 2003; Han, 2004; Yang et al, 2009; 2010). The geometric model of the nozzle was set up by making reference to the geometric construction and dimensions of an 8.5-in PDC bit. Because we focused on the influence of the number of nozzle tangential inlets on jet flow, the nozzle dimensions in the simulation are defined as constants: $16 \mathrm{~mm}$ in exit diameter, and $40 \mathrm{~mm}$ in body length. Tangential inlets are constant in total cross area, and the equivalent diameter equals the nozzle chamber diameter, $18 \mathrm{~mm}$. The length of inlet vents in the nozzle axial direction was modified to ensure the total inlet flow was constant. Because the study is mainly on the jet flow performance and as blades of the bit have less influence on the jet flow, these are neglected in the model. A cylinder $100 \mathrm{~mm}$ in length and $200 \mathrm{~mm}$ in diameter was used to approximate the borehole. The model is built using Pro/E (developed by PTC Company), see Fig. 1.

Importing the model in Fig. 1 into Gambit (developed by FLUENT Company, 1983), the flow field was meshed. The 


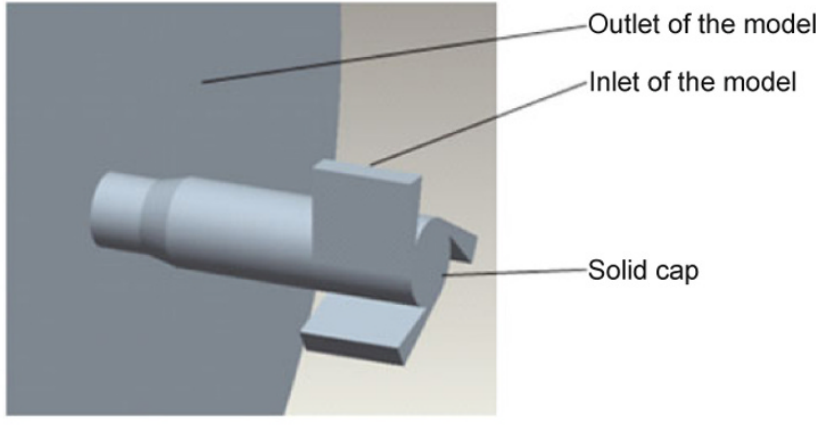

Fig. $13 \mathrm{D}$ flow model for a tangential-inlet nozzle at the bottom hole

critical region in the structured nozzle was refined by local grid refinement (Han, 2004; Yang et al, 2010), see Fig. 2.

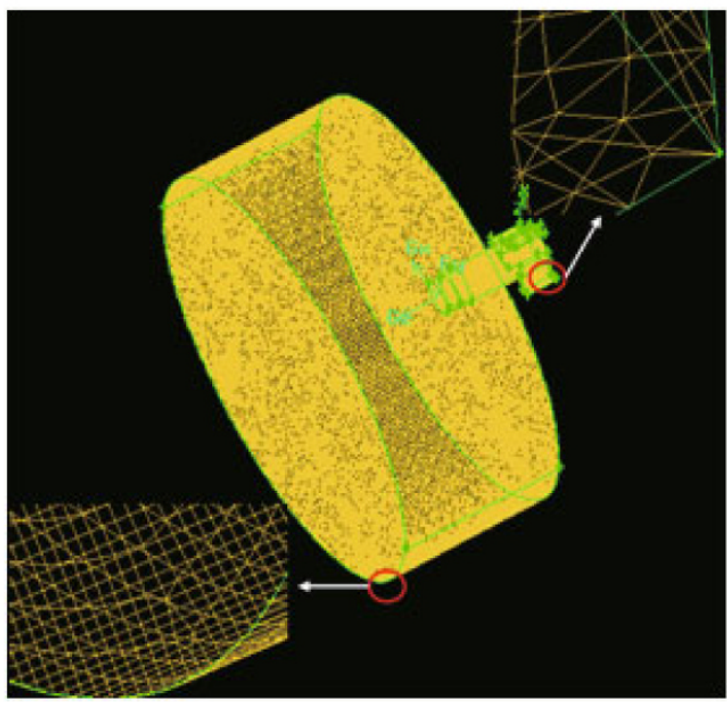

Fig. 2 Meshing of the model

\subsection{Numerical simulation under submerged conditions}

\subsubsection{Problem-solving model}

The standard $k-\varepsilon$ turbulent model was used to solve the flow field, and the governing equations include equations of continuity, momentum equations and $k-\varepsilon$ equations
(Han, 2004; Yang et al, 2009). The model constants are: $C_{1 \varepsilon}=1.44, C_{\mu}=0.99, \sigma_{k}=1.0$, and $\sigma_{\varepsilon}=1.3$.

2.2.2 Computational conditions and boundary conditions 2.2.2.1 Computational conditions

1) Unit of length: $\mathrm{mm}$.

2) Unit of pressure: $10^{5} \mathrm{~Pa}$.

3) Solver setup: a) solver: segregated; b) formulation: implicit; c) space: 3D; d) time: steady; e) velocity formulation: absolute.

4) Fluid material: liquid water copied from the material library of software FLUENT (developed by FLUENT Company, 1983).

\subsubsection{Boundary conditions}

1) Inlet condition of the model: pressure at the nozzle tangential inlet is given, 7.0 $\mathrm{MPa}$.

2) Outlet condition of the model: top cross section of the backflow annulus is the outlet of the model, pressure is given here, $10^{5} \mathrm{~Pa}$.

3) Other boundary conditions of the model: standard wall condition with zero slip velocity components and no penetration.

\subsubsection{Simulation results and discussion}

\subsubsection{Influence of nozzle inlet structure on flow features}

In order to analyze the influence of nozzle inlet structure on flow features, simulations were conducted corresponding to three flow inlet conditions, respectively with $2,3,4$ tangential inlets. The simulation results are shown in Figs. 3 and 4. Fig. 3 demonstrates swirling characteristics of inward flow near the tangential inlets, and Fig. 4 gives the corresponding jet flow out of the nozzle.

Fig. 3 indicates that the inflow streams become a swirling flow after entering the nozzle chamber. The uniformity of swirling flow is influenced by the number of tangential inlets. However, the velocity distribution in Fig. 3 does not show much difference in swirling uniformity. Thus, the number of the tangential inlets of the nozzle has little effect on the swirling flow.

Fig. 4 shows that an increase in the number of the tangential inlets does not make a big difference in the spreading angle and velocity distributions of the downstream jet flow apart from a small increase in tangential velocity. According to the simulation results, spreading angles of the
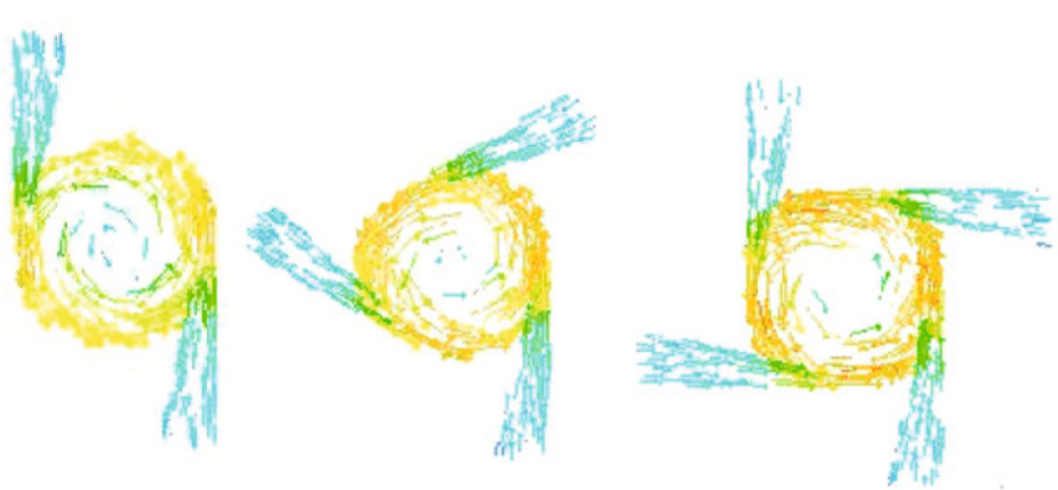

Fig. 3 Comparison of swirling flow near the tangential inlets 


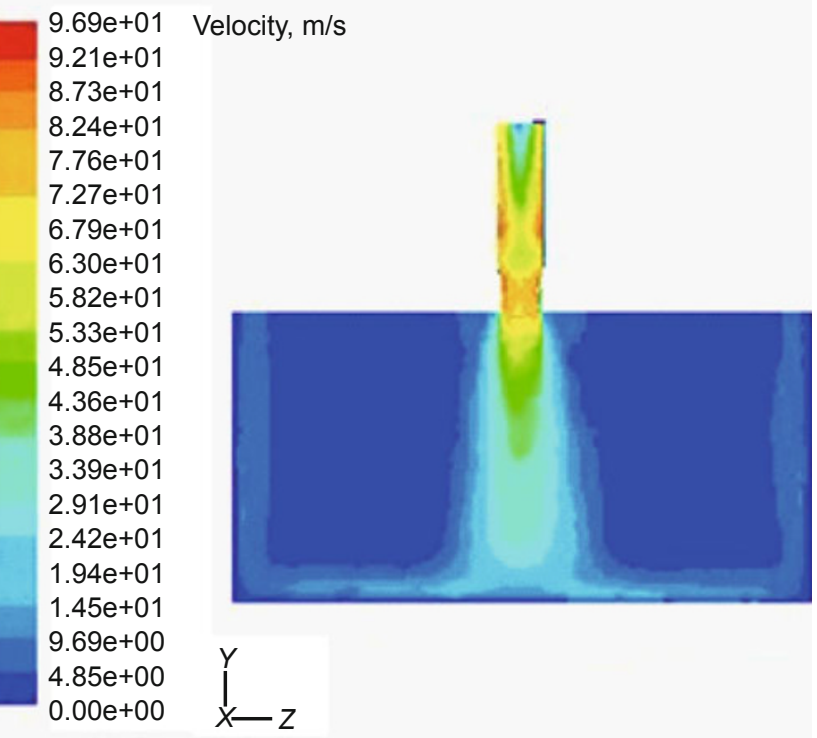

(a) 2 tangential inlets

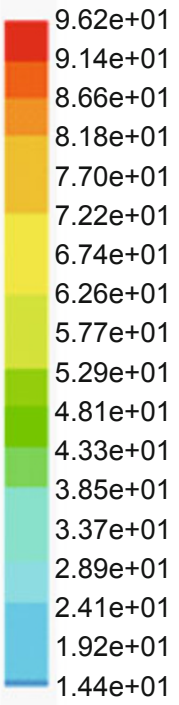

Velocity, $\mathrm{m} / \mathrm{s}$

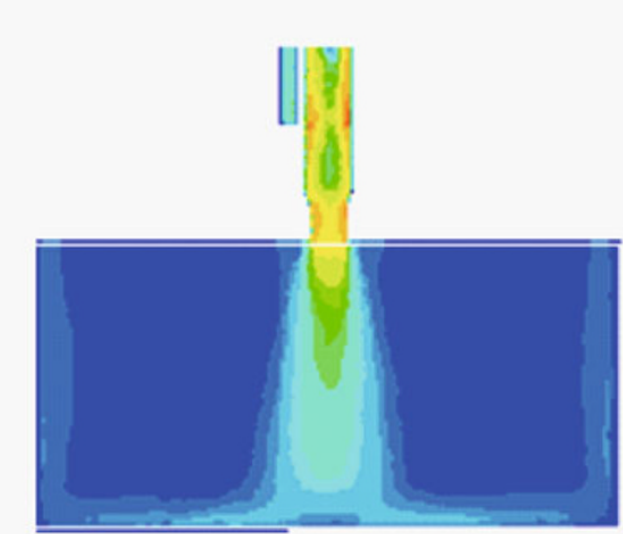

(b) 3 tangential inlets

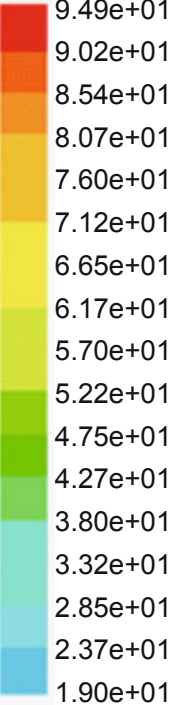

\section{Velocity, $\mathrm{m} / \mathrm{s}$}

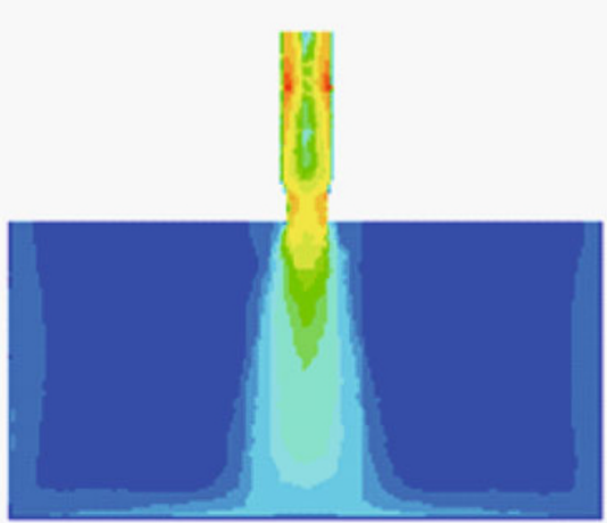

$85 \mathrm{e}+01$

$1.90 \mathrm{e}+01$ swirling jets are about $14^{\circ}-17^{\circ}$, while the spreading angle of the conventional non-swirling jet is generally around $8^{\circ}$ (Yang et al, 1999b; 2001).

2.2.3.2 Influence of nozzle inlet structure on the jet swirling intensity

Swirling intensity is a dimensionless value to show swirling extent of flow. On the cross section of the jet at the nozzle exit, the maximum tangential and axial velocity components were used to calculate the jet swirling intensity (Yang, 2003). Then the change in swirling intensity caused by different nozzle inlet conditions would be compared. By means of simulation results, velocity data could be selected as in Fig. 5, which is corresponding to the velocity distribution of nozzles with 3 tangential inlets. Fig. 5 shows typical distribution modes of the axial velocity and tangential velocity components on the nozzle export section, in forms of "M" and "N" respectively (Yang et al, 1999b; 2005a; Yang, 2003).

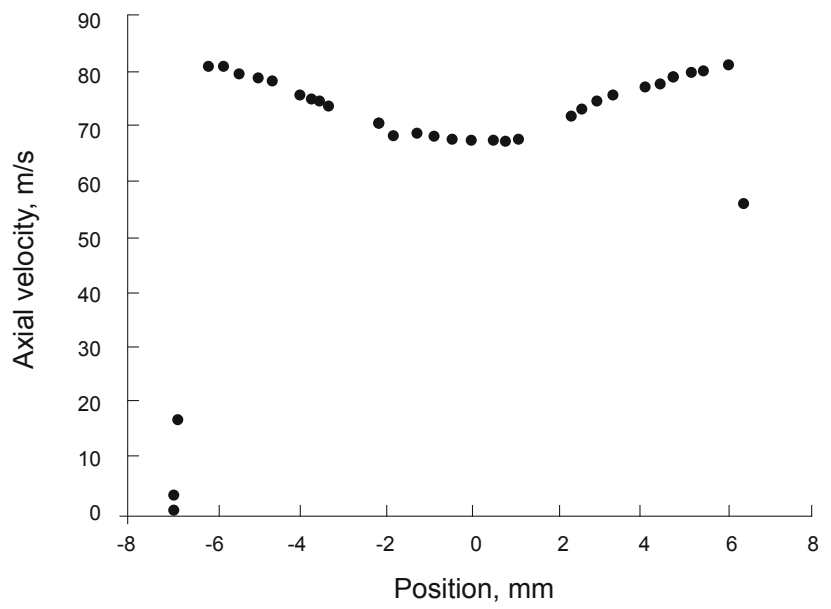

(a) Axial velocity

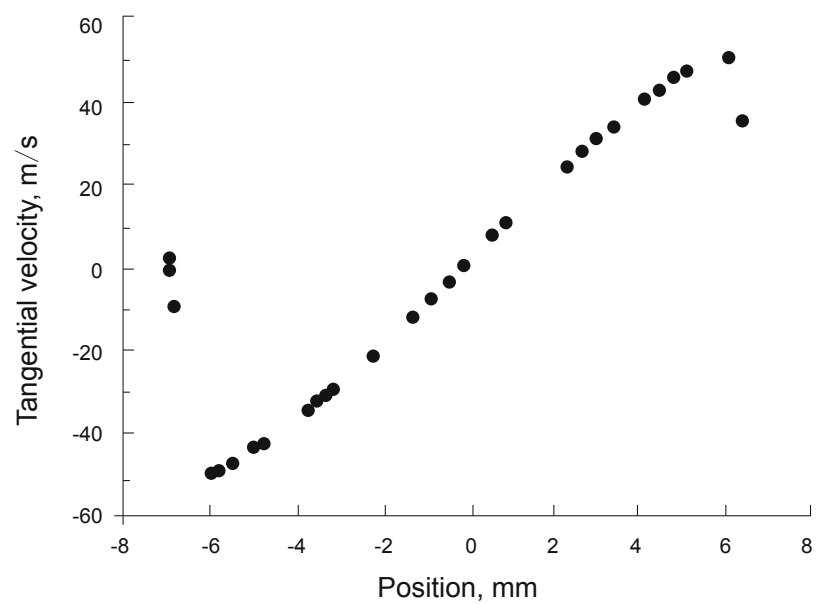

(b) Tangential velocity

Fig. 5 Velocity component distributions at the exit of the nozzle with 3 inlets

According to the definition of swirling intensity, $S^{\prime}=W_{\max } /$ $V_{\max }$ (Yang et al, 2005b; Yang, 2003), jet swirling intensities under all inlet conditions were calculated, see Table 1.

Fig. 4 Comparison of velocity profiles of jets from nozzles with different inlets 
Table 1 Jet swirling intensities with different tangential inlets

\begin{tabular}{cccc}
\hline Nozzle feature & Maximum tangential velocity $W_{\max }, \mathrm{m} / \mathrm{s}$ & Maximum axial velocity $V_{\max }, \mathrm{m} / \mathrm{s}$ & Swirling intensity $S^{\prime}$ \\
\hline 2 inlets & 55 & 86 & 0.64 \\
3 inlets & 54 & 82 & 0.66 \\
4 inlets & 54 & 78 & 0.69 \\
3 inlets, body length doubled & 25 & 80 & 0.31 \\
\hline
\end{tabular}

Table 1 shows that each nozzle generates a powerful swirling stream, and the number of tangential inlets influences the swirling intensity. When the number increases from 2 to 4 , the swirling intensity increases by about $7 \%$. This is because the axial velocity component changes slowly with the number of inlets while the tangential velocity component varies only very slightly. Because of the increase in the inlet number, the axial velocity component decreases but the flow resistance rises.

In addition, Table 1 shows that the jet swirling intensity drops sharply, from 0.66 to 0.31 when the length of the nozzle body is doubled. So nozzles with 3 tangential inlets could be used in the PDC drill bit. And in order to obtain stronger swirling intensity and less flow resistance, the length of the nozzle body should be as short as possible.

\subsubsection{Influence of nozzle inlet structure on the discharge coefficient}

As an important hydraulic factor in drilling design, the discharge coefficient of nozzles is an index to express the total resistance through the nozzle, and it is closely related to the internal geometric structure of nozzles, provided that the Reynolds number of water flow at the nozzle exit is more than the critical value (Shen, 1998). Here the discharge coefficient of nozzles could be calculated with the help of the simulation.

According to the defined nozzle pressure drop, $7.0 \mathrm{MPa}$, the average velocity at the nozzle exit could be calculated in the numerical simulation, and the discharge coefficient of nozzles could be obtained from the following equation. Calculated results are listed in Table 2.

$$
\left\{\begin{array}{l}
Q_{\mathrm{a}}=C Q_{\mathrm{t}} \\
\Delta p=\frac{1}{2} \rho V_{\mathrm{t}}^{2} \\
\left(Q_{\mathrm{a}}, Q_{\mathrm{t}}\right)=\pi D^{2}\left(V_{\mathrm{a}}, V_{\mathrm{t}}\right)
\end{array}\right.
$$

where $Q_{\mathrm{a}}$ and $Q_{\mathrm{t}}$ are the actual flow rate and theoretical flow rate, $\mathrm{m}^{3} / \mathrm{s} ; V_{\mathrm{a}}$ and $V_{\mathrm{t}}$ are the average axial velocities at the nozzle exit obtained respectively from simulation and theoretical calculation for ideal fluid flow, $\mathrm{m} / \mathrm{s} ; \Delta p$ is the nozzle pressure drop, $\mathrm{Pa} ; C$ is the discharge coefficient of the nozzle, dimensionless; $D$ is the nozzle diameter, $\mathrm{m}$.

Table 2 Discharge coefficients corresponding to different nozzles

\begin{tabular}{ccc}
\hline Nozzle feature & $V_{\mathrm{a}}, \mathrm{m} / \mathrm{s}$ & $C$ \\
\hline 2 tangential inlets & 80 & 0.68 \\
3 tangential inlets & 74 & 0.63 \\
4 tangential inlets & 71 & 0.60 \\
Non-swirling jet (cone nozzle) & 112 & 0.95 \\
\hline
\end{tabular}

Table 2 shows that the larger the number of tangential inlets, the smaller the discharge coefficient of nozzles will be, and the discharge coefficients for all nozzles with tangential inlets are much smaller than that of non-swirling jet nozzles. Thus, under the same nozzle pressure drop, enlarging the nozzle diameter of the swirling jet nozzle can obtain the same flow rate as with the non-swirling jet nozzle.

\section{Rock-breaking test}

A rock-breaking test with a water jet is one of the most direct methods for evaluating cuttability of rocks by waterjets (Brook and Summers, 1969; Yang et al, 2005a). The diameter, depth and volume of the cavity created on the test rock per unit time are generally used to evaluate jet performance and the corresponding influences of nozzle geometric parameters.

\subsection{Nozzles}

Based on the simulation results, a swirling-jet nozzle with three tangential inlets was designed and manufactured for the PDC drill bit dimensions (Crouse and Chia, 1985; Sun et al, 2000; Mensa-Wilmot et al, 2006), see Fig. 6. The inlet angle is $30^{\circ}$ in order to reduce inflow resistance, and the equivalent diameter of the total cross section area of the three tangential inlets is slightly bigger than the inside diameter of the swirling jet nozzle. The nozzle exit diameter is $6 \mathrm{~mm}$. During the test, when the tangential inlets are removed, it is transformed into a non-swirling jet nozzle for comparison.

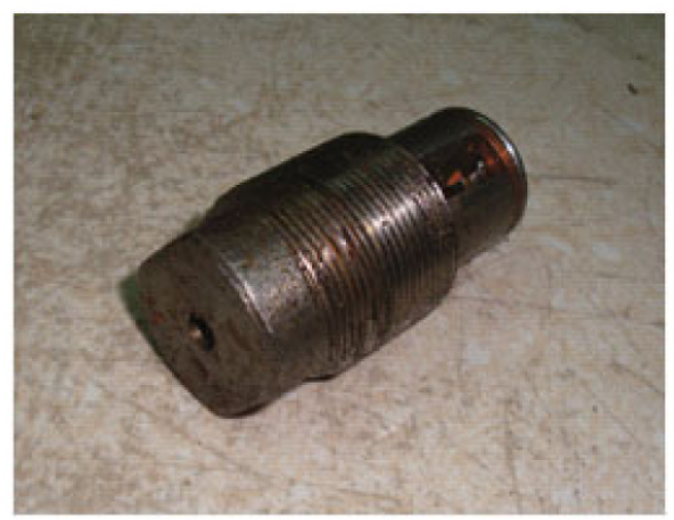

Fig. 6 A nozzle with 3 tangential inlets for swirling jet

\subsection{Test results and discussion}

\subsubsection{Comparison of jets under non-submerged conditions}

Photos of jets under non-submerged conditions are easily taken in order to compare their characteristics. Fig. 7(a) is an image of a swirling jet ejecting from the swirling-jet nozzle 
(Fig. 6), and Fig. 7(b) shows a non-swirling jet from the same nozzle body after the tangential inlets were removed. Both of the jets were ejected under equal nozzle pressure drop, 5.0 $\mathrm{MPa}$. It is clear that the spreading angle and impact area of the swirling jet were obviously far larger than that of the nonswirling jet under non-submerged conditions. Also observed in the test is that the crossflow produced by the swirling jet on the bottom of the tank was more regular than that produced by the non-swirling jet. The former presents the properties of stable flow, while the latter was characterized by much strong turbulence and irregularity. From this phenomenon, it is easy to conclude that the backflow of water after impacting the bottom of hole or cavity also presents strong irregularity and turbulence in drilling with a non-swirling jet, which would severely disturb and prevent the incoming jet flow from a direct impact on the bottom, resulting in lower efficiency of the hydraulic energy.

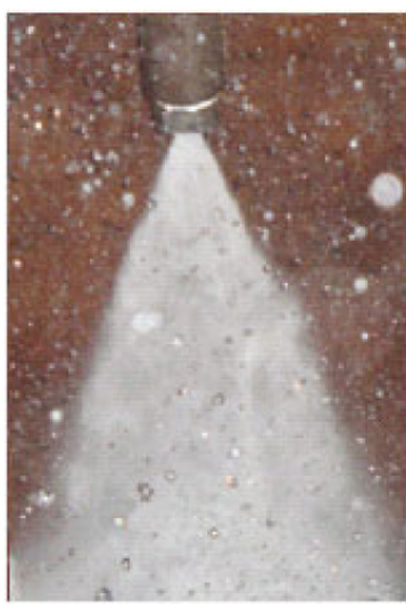

(a) Swirling jet

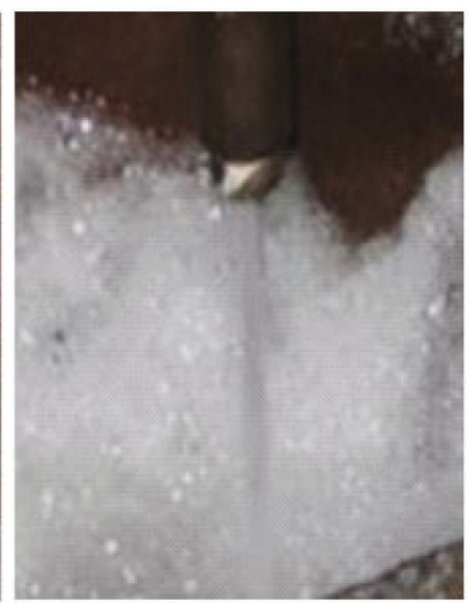

(b) Non-swirling jet
Fig. 7 Comparison of flow characteristics under non-submerged conditions

\subsubsection{Rock breaking test at the same discharge}

Cement blocks were used as rock samples. The ratio of cement to quartz sand was $1: 3$. The artificial rock samples had a compressive strength of about $41 \mathrm{MPa}$ corresponding to a quartz sandstone of moderate hardness (Yang et al, 1999b; 2005a; 2005b; Wu et al, 2010). In the tests for both swirling jet and non-swirling jet nozzles, the water discharge rate and impact time were $160 \mathrm{~L} / \mathrm{min}$ and $4 \mathrm{~min}$, respectively, and the standoff distance of the nozzle away from rock samples was $28 \mathrm{~mm}$, almost equal to the nozzle practical standoff distance from the cutting face on an 8.5-in PDC drill bit.

In the tests, because the swirling jet nozzle has a smaller discharge coefficient, its pressure drop was $9.5 \mathrm{MPa}$, larger than 7.2 MPa for the non-swirling jet nozzle after the tangential inlets being removed, which is in accordance with the aforementioned simulation results. The cavities generated in the same cement block respectively with two jets are much different, see Fig. 8. Performance of the two nozzles is listed in Table 3.
Table 3 Performance of nozzles at the same discharge

\begin{tabular}{cccc}
\hline Jet type & $\begin{array}{c}\text { Cavity diameter } \\
\mathrm{mm}\end{array}$ & $\begin{array}{c}\text { Cavity depth } \\
\mathrm{mm}\end{array}$ & $\begin{array}{c}\text { Cavity volume } \\
\mathrm{mL}\end{array}$ \\
\hline Swirling jet & 47.6 & 21 & 25 \\
Non-swirling jet & 15 & 13 & 5 \\
\hline
\end{tabular}

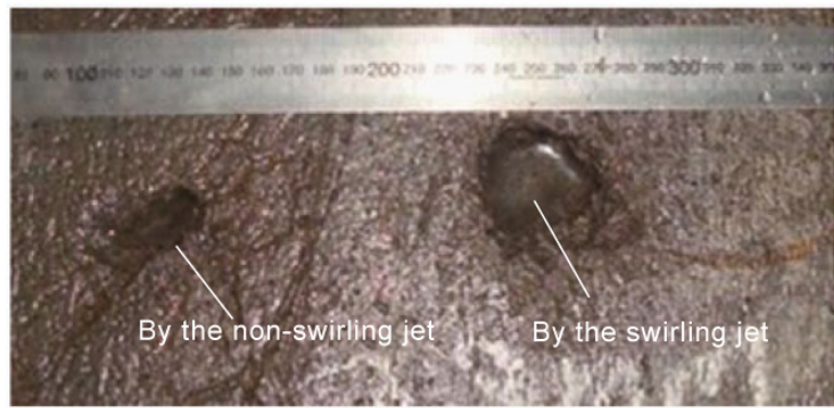

Fig. 8 Comparison of cavities created in the same rock sample at the same discharge

In Table 3, the cavity diameter means the diameter of the main cavity, not including the delaminated part around the main cavity. The cavity volume is the whole cavity volume removed by jet. Table 3 shows that the cavity volume created by the swirling jet was 5 times that by the non-swirling jet under the test conditions.

3.2.3 Rock breaking test at the same nozzle pressure drop

Another similar cement block was used in this test. The nozzle pressure drop was controlled at 7.0 $\mathrm{MPa}$, impact time $5 \mathrm{~min}$, and the standoff distance $28 \mathrm{~mm}$.

In the test, when the non-swirling jet was applied, no clear cavity was visible. In Fig. 9, the region marked with the white line was the impact area created by the non-swirling jet, and the big cavity was created by the swirling jet.

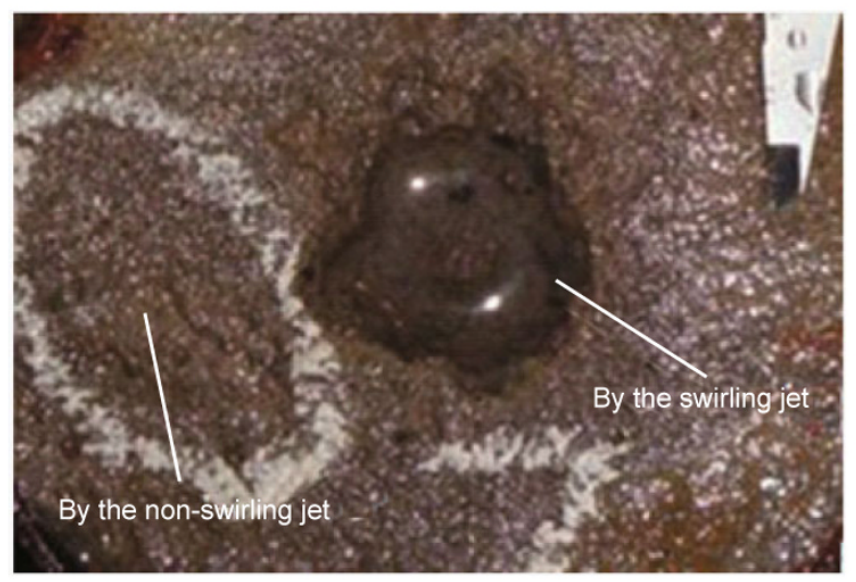

Fig. 9 Comparison of rock breaking at the same nozzle pressure drop

Fig. 9 and Table 4 demonstrate that the threshold pressure necessary to break the rock with the swirling jet was lower than that required when cutting with the non-swirling jet. The non-swirling jet can break the rock sample at 7.2 $\mathrm{MPa}$ (see Fig. 8), but cannot at 7.0 MPa, which shows that the threshold 
pressure for the non-swirling jet was more than 7.0 $\mathrm{MPa}$ but less than 7.2 $\mathrm{MPa}$. Obviously, the threshold pressure of the rock sample was lower than 7.0 $\mathrm{MPa}$ for the swirling jet.

Table 4 Performance of nozzles at the same nozzle pressure drop

\begin{tabular}{cccc}
\hline Jet type & $\begin{array}{c}\text { Cavity diameter } \\
\mathrm{mm}\end{array}$ & $\begin{array}{c}\text { Cavity depth } \\
\mathrm{mm}\end{array}$ & $\begin{array}{c}\text { Cavity volume } \\
\mathrm{mL}\end{array}$ \\
\hline Swirling jet & 53 & 17 & 15 \\
Non-swirling jet & - & $\approx 0$ & $\approx 0$ \\
\hline
\end{tabular}

\section{Conclusions}

In this paper, the nozzle performance influenced by nozzle geometric parameters was numerically simulated with CFD software-FLUENT and rock breaking tests were conducted under submerged conditions in order to ensure a swirling jet can be applied to a PDC drill bit.

1) By means of numerical simulation, the spreading characteristics of the swirling jet generated from nozzles with tangential inlets, and the influences of nozzle structure on both swirling intensity and discharge coefficient were obtained. The spreading angle of the swirling jet was much greater than that of the non-swirling jet. The number of tangential inlets of the nozzle had little influence on the swirling intensity, while the increase in the length of the nozzle body would sharply reduce the swirling intensity.

2) Comparisons of rock breaking tests under either the same discharge or the same nozzle pressure drop, illustrate that the swirling jet has a higher ability to break the rock samples and a lower rock breaking pressure than a nonswirling jet.

3) The swirling jet nozzle had a lower discharge coefficient than a non-swirling jet nozzle. In practice, increasing the diameter of the swirling jet nozzle could achieve the required discharge rate.

\section{Acknowledgements}

The authors are grateful for the financial support from the Fundamental Research Funds for the Central Universities and the Natural Science Foundation of China (51179201).

\section{References}

Brook N and Summers D A. The penetration of rock by high-speed water jets. International Journal of Rock Mechanics and Mining Science. 1969. 6(June): 249-258

Crouse R and Chia R. Optimization of PDC bit hydraulics by fluid simulation. Paper SPE 14221-MS presented at SPE Annual Technical Conference and Exhibition, 22-26 September 1985, Las Vegas, Nevada

Han Z Z. Engineering Cases and Applications of Simulation of Flow with FLUENT. Beijing: Beijing Institute of Technology Press. 2004. 1-20 (in Chinese)

Mensa-Wilmot G, Mikhail B, Al-Saeedi M, et al. Innovative design process and technologies improve PDC bit performance in harsh drilling environments. Paper SPE 103983-MS presented at IADC/
SPE Asia Pacific Drilling Technology Conference and Exhibition, 13-15 November 2006, Bangkok, Thailand

Shen Z H. Water Jet Theory and Technique. Dongying: China University of Petroleum Press. 1998. 390-413 (in Chinese)

Shen Z H, Wang R H and Yang Y Y. Water jet technology in petroleum engineering. Presented at the Proceedings of the 8th Pacific Rim International Conference on Water Jetting Technology, 10-12 October 2006, Qingdao, China

Sun M G, Zhang Y L, Yang Y K, et al. New cutting structure design improves the penetration of the PDC bits. Paper SPE 62858-MS presented at SPE/AAPG Western Regional Meeting, 19-22 June 2000, Long Beach, California

Taylor M R, Murdock A D and Evans S M. High penetration rates and extended bit life through revolutionary hydraulic and mechanical design in PDC drill bit development. SPE Drilling \& Completion. 1999. 14(1): 34-41 (Paper SPE 55047)

Wu A, Hareland G and Rashidi B. The effect of different rock types and roller cone insert types and wear on ROP (rate of penetration). Paper American Rock Mechanics Association 10-207 presented at 44th U.S. Rock Mechanics Symposium and 5th U.S.-Canada Rock Mechanics Symposium, 27-30 June 2010, Salt Lake City, Utah

Yang H B, Yang Y Y, Shen Z H, et al. Experimental study of rock drilling with abrasive suspension swirling jet. Journal of the University of Petroleum, China. 2005a. 29(3): 45-48 (in Chinese)

Yang Y Y, Shen Z H, Wang R H, et al. Experimental study on rockbreaking and drilling with swirling abrasive jet. Journal of Petroleum Drilling Techniques. 1999a. 27(4): 1-5 (in Chinese)

Yang Y Y, Shen Z H, Wang R H, et al. Research on mechanisms of rockbreaking and drilling with swirling jet. Journal of China Safety Science. 1999b. 9(special issue): 4-6, 8 (in Chinese)

Yang Y Y, Wang R H, Zhou W D, et al. Experimental studies on swirling jet for hole drilling. Presented at the Proceedings of the 2001 WJTA American Water-Jet Conference, 18-21 August 2001, Minneapolis, Minnesota, Paper No. 48

Yang Y Y, Wang R H and Shen Z H. Experimental study of velocity profile of submerged abrasive suspension jet flow. Journal of Hydrodynamics. 2002. 14(1): 69-74

Yang Y Y. Abrasive Suspension Swirling Jet Flow Property and Its Application in Drilling. Doctoral Dissertation. China University of Petroleum (Beijing). 2003 (in Chinese)

Yang Y Y, Zhou W D, Wang R H. et al. Rock drilling with abrasive suspension swirling jet and effects of additive polyacrylamide. Presented at the Proceedings of 2005 American Water Jet Conference, August, 2005b, Houston, Texas

Yang Y Y, Wang R H and Shen Z H. Experiments on negative pulse jetting assisted drilling. Presented at the Proceedings of the 8th Pacific Rim International Conference on Water Jetting Technology, 10-12 October 2006, Qingdao, China

Yang Y Y, Wu Q, Wang X Y, et al. Numerical simulation of nonsubmerged swirling jet. Presented at the 13th National Water Jet Technology Research and Application Conference, December 2009, Beijing, China (in Chinese)

Yang Y Y, Pei J Z, Sun W L, et al. Research on mechanism of improving bottom-hole flow field by using jet. Basic Drilling Theory and New Development of Frontier Technology Conference. 24-26 October 2010, Chengdu, China (in Chinese)

Zhou W D, Wang R H, Yang Y Y, et al. The experimental study of oil \& gas well casing cutting with abrasive water jet. Presented at the Proceedings of the 7th Pacific Rim International Conference on Water Jet Technology, 27-29 October 2003, 266-272

(Edited by Sun Yanhua) 